\title{
A METODOLOGIA DE LAMARCK
}

\author{
Lilian Al-Chueyr Pereira MARTINS \\ Roberto de Andrade MARTINS ${ }^{1}$
}

- RESUMO: Neste artigo, o método científico de Jean-Baptiste Lamarck é estudado sob o ponto de vista de seu discurso metodológico, bem como sob o ponto de vista de sua prática científica. Essa metodologia é comparada à preconizada por Condillac, assim como à dos "ideólogos" (idéologues) grupo no qual se costuma incluir o próprio Lamarck. Mostra-se que o discurso metodológico de Lamarck assemelha-se ao dos ideólogos; no entanto, sua prática científica não se coaduna com esse enfoque. Em vez de seguir uma abordagem empirista, a obra de Lamarck se fundamenta em princípios metafísicos gerais sobre a natureza. Sob o ponto de vista dos ideólogos, seu trabalho deveria ser rejeitado - o que de fato ocorreu - como um mero sistema (système) metafísico - no sentido pejorativo utilizado pelos seguidores de Condillac. No entanto, o presente artigo argumenta que esse é justamente um importante e inovador aspecto da obra de Lamarck, que permitiu a eclosão do evolucionismo moderno.

- PALAVRAS-CHAVE: Lamarck; Condillac; empirismo; método científico; evolucionismo; filosofia francesa - século XIX; ideólogos.

\section{Introdução}

Jean-Baptiste Pierre-Antoine de Monet, chevalier de Lamarck (1744-1829) é, atualmente, conhecido como um dos precursores do evolucionismo biológico; no entanto, sua obra é pouco estudada e seu nome é usualmente associado, por uma contingência histórica, ao lamarckismo - a concepção de que as características adquiridas por um indivíduo durante sua vida são herdadas por seus descendentes. ${ }^{2} \mathrm{~A}$ contribuição de Lamarck, no entanto, é muito maior do que isso. Ao longo de duas

1 Grupo de História e Filosofia da Ciência, DRCC-IFGW - Unicamp - 13081-970 - Campinas - SP.

2 Uma concepção como essa faz parte, de fato, da teoria de Lamarck; no entanto, a herança de caracteres adquiridos não é um dos aspectos principais da sua teoria; não foi proposta pela primeira vez por Lamarck (já era aceita desde Hipócrates) e foi aceita também por Charles Darwin e por quase todos os naturalistas do século XIX. Ver, sobre esse tema, o artigo de Zirkle, 1946. 
décadas e em diferentes publicações, ${ }^{3}$ ele desenvolveu uma teoria bastante detalhada sobre a progressão dos seres vivos, ${ }^{4}$ procurando fundamentá-la por meio de estudos geológicos e zoológicos. Embora, antes de Lamarck, outros autores tenham sugerido a possibilidade de transformação progressiva dos seres vivos, nenhum naturalista havia proposto um sistema teórico completo defendendo tal visão.

Sabemos que a teoria desenvolvida por Lamarck não é aceita atualmente e que a teoria evolucionista atual é baseada principalmente no trabalho de Darwin. No entanto, uma obra científica não deve ser avaliada anacronicamente, tomando-se como base o que a ciência atual aceita ou não. Ela deve ser analisada em seu próprio contexto histórico, procurando verificar se, de acordo com os conhecimentos e a metodologia adotada na época, era bem fundamentada e representava um importante avanço, ou não.

É especialmente difícil avaliar o trabalho de Lamarck porque, sendo um cientista e não um filósofo, ele não é muito sistemático nem explícito com relação aos pressupostos e método utilizados. De um modo geral, Lamarck tem sido considerado um membro do grupo dos idéologues - os empiristas franceses do final do século XVIII e início do século XIX que se inspiravam na obra de Condillac. Se Lamarck adotava uma posição empirista como essa, então a análise de sua obra científica deveria verificar basicamente se ele procurou se ater aos fatos e a generalizações mais diretas dos fatos observáveis, e se sua teoria estava bem justificada, desse ponto de vista. Por outro lado, um importante estudioso moderno de Lamarck - Léon Szyfman - argumenta que ele desenvolveu um novo tipo de método, oposto ao de Condillac, devendo por isso ser julgado sob outro prisma. Entretanto, paradoxalmente, esse mesmo autor o classifica como um ideólogo.

O objetivo do presente trabalho é estudar a metodologia científica de Lamarck, comparando-a com as concepções de Condillac e as dos ideólogos. Nos limites de espaço compatíveis com um artigo, será impossivel, é claro, fazer uma discussão da própria teoria científica de Lamarck.

\section{A metodologia de Lamarck}

Como se pode avaliar o trabalho de um pesquisador? Não faria sentido avaliar Lamarck com base em alguma metodologia atual ou na visão epistemológica de algum filósofo atual. É necessário conhecer e discutir a metodologia utilizada por ele em seu

3 Lamarck produziu uma obra vastíssima. Publicou trabalhos sobre meteorologia, botânica, paleontologia, física, zoologia e filosofia. As obras de Lamarck que constam da lista bibliográfica deste artigo são apenas as mais relevantes, do ponto de vista do tema aqui tratado. Uma excelente visão geral de sua obra pode ser encontrada em Landrieu, 1908. Ver também, a respeito, Martins, 1993.

4 Lamarck nunca utilizou a palavra "evolução" para se referir às suas próprias idéias. Em vez desse termo, ele emprega muitas vezes as expressões "progressão" "progresso" etc. 
próprio trabalho. Essa metodologia pode ser considerada sob dois aspectos. Um deles é aquele que se apresenta explicitamente, no que poderíamos chamar "discurso metodológico" do autor; ou seja, aquilo que ele afirma estar fazendo ou que deve ser feito. O outro aspecto é o que se pode extrair da análise da própria prática do autor; ou seja, a sua praxis ou metodologia prática, a descrição de seu efetivo procedimento ao desenvolver a sua pesquisa. A prática pode ser coerente com o discurso metodológico, ou não. Uma crítica realmente séria da obra de Lamarck é impossível sem esse tipo de distinção, pois não se pode querer censurá-lo adotando uma visão de ciência incompatível com a sua. Pode-se, sim, criticá-lo, se ele não pratica aquilo que diz ser o método científico correto. Vamos iniciar, portanto, pela análise do seu discurso metodológico.

Lamarck diferencia rigidamente fato e teoria. Para ele, os fatos poderiam ser estabelecidos de forma totalmente segura, enquanto as teorias não, sendo sempre duvidosas. Além disso, Lamarck utiliza também o termo "fato positivo", que surgiu e foi empregado antes do positivismo propriamente dito. ${ }^{5}$

Lamarck explica o que considera conhecimentos positivos:

Quanto a mim, convencido de que os únicos conhecimentos positivos que podemos ter, não são outros senão os adquiridos pela observação, sabendo por outro lado que fora da natureza, fora dos objetos que são de seu domínio e dos fenômenos que nos oferecem esses objetos, não podemos observar nada, impus-me por regra, em relação ao estudo da natureza, deter-me em minhas pesquisas apenas quando os meios não me faltarem inteiramente. (1835-1845, v.1, p.138)

\section{O conceito de fatos positivos é assim apresentado por Lamarck na Philosophie zoologique: 6}

Para o home m não existem realmente verdades positivas (quer dizer, aquelas com as quais ele possa contar solidamente), a não ser os fatos que ele pode observar, e não as conseqüências deles tiradas; apenas a existência da natureza que lhe apresenta esses fatos, assim como as leis que regem os movimentos e as mudanças de suas partes. Fora disso, tudo é incerteza; embora certas conseqüências, teorias, opiniões, etc., tenham uma probabilidade muito maior do que outras. (1907a, v.1, p.xxv)

De acordo com essa posição, haveria um domínio de certeza total, sobre os fatos positivos e as leis; e um domínio de probabilidade e incerteza, sobre as teorias e opiniões. Os "fatos positivos" são definitivos: "Esses são fatos positivos, verdades que nada têm a temer de um exame aprofundado" (1835-1845, v.1, p.61).

5 O positivismo "clássico" de Auguste Comte foi fortemente influenciado pela corrente dos "ideólogos" franceses, com os quais ele estudou e entre os quais se inclui, comumente, Lamarck.

6 A parte introdutória da Philosophie zoologique contém em grande extensão uma descrição da posição metodológica de Lamarck. As citações dessa obra, aqui inseridas, referem-se à paginação da edição de 1873, para o segundo volume, e a paginação da edição de 1907, para a primeira parte. Quando aparecer Zoological Philosophy estamos nos referindo à tradução de Hugh Elliot. 
Como não se pode contar com nenhum raciocínio, nenhuma conseqüência, nenhuma teoria, pois os autores desses atos de inteligência não podem ter a certeza de ter empregado os verdadeiros elementos que deveriam constitui-la, de não ter introduzido nada além deles e de não ter negligenciado nenhum - uma vez que para nós só existe de positivo a existência de corpos que possam afetar nossos sentidos, as qualidades reais que lhes são próprias, enfim os fatos físicos e morais que podemos conhecer - os pensamentos, os raciocínios e as explicações que se encontram expostos nesta obra deverão ser considerados apenas como simples opiniões que eu proponho, com a intenção de anunciar o que me parece ser e o que poderia efetivamente ter acontecido. (1907a, v.1, p.xxv-vi)

Assim, Lamarck distingue, em sua própria obra, a existência tanto de verdades "positivas" - seguras, indubitáveis -, quanto de "simples opiniões". O domínio dos conhecimentos positivos abrangeria os "fatos físicos e morais", ou seja, aquilo que se conhece diretamente sobre o mundo externo (físico). Apesar de valorizar bastante os fatos, Lamarck afirma que a pesquisa não deve se restringir apenas a descrevê-los. Os fatos podem ser explicados por meio de leis, que também são fatos positivos. Esse também é o discurso de Condillac, que defende a observação e a experimentação guiadas por questões claras, levando a leis cada vez mais gerais, capazes de explicar um grande número de fenômenos (ver, "La logique", p.412, e "De l'art de raisonner", p.637, in Condillac, 1947-1951, v.2 e 1).

Para Lamarck, embora importantes, as teorias não são seguras. Assim, ele indica as condições em que abandonaria a sua própria teoria:

Não pretendo anular as opiniões que descartei; mas como a maior parte delas parece incompativel com as conseqüências a que cheguei, simplesmente ofereço aqui o conjunto dessas conseqüências, pelo valor que elas possam ter. Tudo o que posso dizer é que, se essas conseqüências são tão fundamentadas quanto me parecem, as opiniões que elas repelem são todas errôneas, ou, se não for assim, a minha teoria deve ser totalmente rejeitada como sendo sem fundamento. Entretanto, enquanto uma demonstração rigorosa não se pronunciar por sua rejeição, eu seguirei os seus princípios, não me permitindo culpar aqueles que crêem dever rejeitá-los. (1820, p.3)

Embora Lamarck tenha confiança em sua própria teoria, ele não a coloca contudo como algo final, mas algo que poderia ser rejeitado como desprovido de fundamento se fosse possivel demonstrar rigorosamente que suas conseqüências são falsas.

Esse discurso metodológico que permeia a obra de Lamarck não é muito original, como se pode perceber. Lamarck foi altamente influenciado por Étienne Bonnot, abbé de Condillac (1714-1780). O discurso metodológico de Lamarck é, em grande parte, o discurso de Condillac e, nesse sentido, ele pode ser considerado empirista. Há, entretanto, alguns aspectos discordantes: Condillac não utiliza o termo "fatos positivos", que é central em Lamarck. Mas a semelhança e a dependência são inegáveis. Lamarck, em sua obra, refere-se respeitosamente a Condillac (ver 1907b, p.562, por exemplo), recomendando que seu método de análise seja seguido. Nota-se, ainda, 
uma influência de Buffon, que, como Condillac, também preconizava o apego aos fatos evitando-se as especulações e propunha um estudo dos fatos seguido pela sua sistematização e correlação criando-se um sistema - aquilo que hoje chamaríamos teoria (ver "Traité des systèmes", in Condillac, 1947-1951, v.1, p.207; e Buffon, 1954, p.26, por exemplo).

\section{Lamarck e os idéologues}

A partir do discurso metodológico de Lamarck, ele poderia ser caracterizado como um empirista, seguidor de Condillac. Por esse motivo, normalmente ele é considerado um dos componentes do grupo de ideólogos. ${ }^{7}$

A influência de Condillac no pensamento francês teve grande importância no grupo dos chamados "ideólogos", no período da Revolução e, posteriormente, durante o Império (cf. Le Roy, 1947-1951, v.1, p.vii-xxxv, especialmente p.xxxi). Dentre seus seguidores desse período, podem ser citados Volney, Ginguené, Garat, Destutt de Tracy, Cabanis, Degérando, Laromiguière e outros. ${ }^{8}$ É exatamente nesse período de maior influência de Condillac que Lamarck formula suas idéias.

A corrente filosófica dos "ideólogos" franceses não costuma merecer grande atenção dos historiadores da filosofia. Como observa Picavet, eles são usualmente deixados de lado ou atacados, mas pouco estudados (1891, p.ix). Eles são caracterizados principalmente pela presença de uma constante preocupação e análise dos processos de pensamento (o desenvolvimento de idéias), daí vindo o seu nome coletivo. Os ideólogos se baseiam no exemplo de Condillac, sem no entanto adotá-lo cegamente. Foram também fortemente influenciados pela Encyclopédie de Diderot e de D'Alembert. Em sua maioria, localizavam-se na École Polytechnique e no Institut, tendo se tornado a mais forte corrente francesa no início do século XIX.

Em sua obra sobre os ideólogos, Picavet (1891, p.vii) inclui entre eles a pessoa de Lamarck. Um dos motivos dessa inclusão é, sem dúvida, que Lamarck pertenceu ao Instituto (fez parte de sua seção de botânica) e pertencia ao mesmo círculo social e intelectual que os idéologues; mas, estranhamente, Picavet jamais discute o critério que o leva a incluir algum nome entre os ideólogos.

Embora influenciados por Condillac, os ideólogos se distanciam dele em alguns aspectos. Mais empiristas do que seu mestre, eles se recusam a aceitar qualquer teorização ou sistematização mais ampla, adotando nesse ponto a posição de D'Alembert:

7 Ver, por exemplo, Picavet, 1891, p.viii e Szyfman, 1982, cap.IV, especialmente p.57 e cap.XIX. Ver, também, Ricken, 1986, p.39.

8 Segundo Le Roy, esses Ideólogos adotam apenas uma parte e não toda a atitude de Condillac com relação à ciência: enfatizam a "experiência positiva", condenam a metafísica e permanecem fiéis a um "método objetivo", como propunha Condillac. Entretanto, dedicam-se a um empirismo limitado, apreciando a variedade e a heterogeneidade dos fatos mostrados pela observação, sem buscar sua sistematização, sem procurar as leis mais gerais e unificadoras da experiência (1947-1951, p.xxxii). 
o gosto pelos sistemas, mais adequados para agradar a imaginação do que para esclarecer a razão, está hoje quase absolutamente banido das boas obras. Um de nossos melhores filósofos, o abbé de Condillac, parece lhe haver dado os últimos golpes. (1864, p.114)

A física está portanto limitada unicamente às observações e aos cálculos; a medicina, à história do corpo humano ... a história natural, à descrição detalhada dos vegetais, dos animais e dos minerais ... em uma palavra, todas as ciências limitadas, tanto quanto possível, aos fatos e às consequiências que podem ser deduzidas deles, nada cedem à opinião, a não ser quando forçadas. (p.115-6)

Como se vê, D'Alembert generalizou exageradamente a crítica de Condillac aos sistemas. "Sistema" tornou-se, no final do século XVIII, quase um palavrão. Uma das figuras centrais dos idéologues, Destutt de Tracy, assim resume a concepção de seu grupo:

Os alemães acreditam que todos, sem metafísica, somos discípulos de Condillac ... É ao método e não às decisões de Condillac que damos grande importância ... Este método nos mostra por que não devemos contruir sistemas ${ }^{9} . .$. Ele consiste em observar os fatos com o maior escrúpulo, a deles não tirar consequêencias senão com total confiança, a jamais dar a simples suposições a consistência de fatos, a só tentar ligar entre si as verdades quando elas se encadeiam naturalmente e sem lacuna, a evitar francamente aquilo que não se sabe e a preferir sempre a ignorância absoluta a toda afirmação que seja apenas verossímil... (apud Picavet, 1891, p.22)

O método geral empregado pelos ideólogos em seus estudos é exemplificado por Picavet a partir do trabalho de Destutt de Tracy:

ele se recusa a afirmar ou negar a sensibilidade dos vegetais ou animais, pois temos uma completa ignorância a esse respeito e a boa filosofia não deve supor nada; a sensibilidade e a memória são o resultado de uma organização cujas molas secretas (ressorts secrets) são impenetráveis para nós. Temos que representar a força vital como o resultado de atrações e combinações químicas, que dão nascimento, por algum tempo, a um tipo de fatos particulares, mas que caem sob o domínio de leis mais gerais, que são as da matéria inorgânica; não sabemos em que ela consiste ${ }^{10}$... A única coisa útil é estudar o que existe, para conhecê-lo e tirar daí o partido mais vantajoso, sem se empenhar na pesquisa das causas e das origens, fonte inesgotável de erros e enganos. (1891, p.336-7)

Vemos que o empirismo mais limitado dos ideólogos estabelece barreiras ao conhecimento que não são aceitas por Lamarck. Se aceitasse essa posição, ele não poderia discutir se os animais ou vegetais possuem ou não sensibilidade - e, no entanto, ele estuda e procura resolver esse problema; não poderia discutir a natureza da vida - e, no entanto, ele procura estabelecer qual é essa natureza; não poderia construir sistemas - e, no entanto, Lamarck dá este título à sua última obra: Système

9 De Tracy, como outros ideólogos, distorce o pensamento de Condillac, sob este aspecto. Condillac censura os sistemas que se baseavam em principios abstratos ou em hipóteses, mas defende a construção de sistemas fundamentados sobre fatos gerais (leis).

10 Os trechos relevantes encontram-se na obra Élements d'idéologie, de Destutt de Tracy, apud Picavet (p.28-9e 233-4) 
analytique des connaisances positives de l'homme. Certamente, Lamarck não é um seguidor da ideologia de Destutt de Tracy.

Em uma seção de sua obra, Picavet descreve o pensamento de Lamarck (p.43844). No entanto, em vez de discutir sua metodologia, como seria de esperar em um estudo de história da filosofia, ele se restringe a expor concisamente as concepções científicas de Lamarck. Em um comentário passageiro, Picavet afirma que, "por seu método, ele [Lamarck] se associa a Descartes, a Condillac, ${ }^{11}$ a Cabanis, a Buffon. Mas ele tem sua originalidade..." (p.440, nota de rodapé). Mas não explica essa semelhança de Lamarck com outros autores, nem esclarece qual a sua originalidade metodológica.

A principal obra metodológica de Cabanis é Du degré de certitude de la médecine. Esta obra foi escrita em 1788 e sua publicação estava prevista para 1789, mas foi adiada em virtude da Revolução Francesa, só aparecendo vários anos depois.

Neste trabalho, Cabanis indica várias objeções contra a certeza da medicina, para discuti-las depois. Algumas dessas objeções são: nossa incapacidade de conhecer as "molas secretas" dos seres vivos e, portanto, o desconhecimento de como atua a vida; nossa ignorância das causas primeiras das doenças; e a natureza igualmente desconhecida dos remédios e do seu modo de agir nos organismos. Cabanis admite todas essas limitações do conhecimento, mas defende a possibilidade de um conhecimento médico baseado nos fenômenos observáveis:

É certo, por um lado, que a natureza da causa que move os corpos animados e que as circunstâncias imediatas que modificam sua influência nos diversos órgãos se ocultam igualmente às nossas pesquisas e nos são totalmente desconhecidas. É certo que se seu conhecimento deve servir de base à arte de curar, a arte peca essencialmente pela sua base. A questão se reduz portanto a saber se é necessário, ou pelo menos se seria muito vantajoso, penetrar na própria essência das forças vitais e ter uma idéia precisa sobre a maneira pela qual elas agem sobre os corpos.

O homem não conhece a essência de nada, nem a da matéria queeletem incessantemente sob os olhos, nem a do princípio secreto que a vivifica e determina todos os fenômenos do universo. Ele fala freqüentemente das causas de que se vangloria de haver descoberto e daquelas que ele lamenta não poder descobrir: mas as verdadeiras causas, as causas primeiras, estão tão ocultas para ele quanto a própria essência das coisas; ele não conhece nenhuma. Ele vê efeitos, ou melhor, ele recebe sensações; ele observa as relações, seja entre os objetos aos quais ele atribui essas sensações, seja entre esses objetos e si próprio: ele se esforça por perceber incessantemente novas relações ... Examinando essas pretensas causas, cujo conhecimento o envaidece, vê-se que, no fundo, elas todas não passam de fatos. Dois fatos se encontram encadeados um ao outro em uma ordem de sucessão: diz-se que o primeiro é a causa do segundo.

Ignoro portanto as causas. Mas a observação me ensina que tudo se realiza na natureza de um modo regular e constante; que em circunstâncias absolutamente semelhantes, os fatos são sempre os mesmos... ([1803], p.57-9, 62)

11 É absurdo comparar Lamarck, simultaneamente, a Descartes e a Condillac, cujos métodos são muito diferentes. 
Nota-se, em Cabanis, como em todos os outros ideólogos, uma clara admissão da existência de limitações para a investigação humana: a impossibilidade de captar as verdadeiras causas, de conhecer a verdadeira natureza das coisas. Deve-se evitar formular hipóteses sem fundamento sobre esses pontos, e procurar restringir a ciência aos fatos.

Podemos ver que Lamarck compartilha de algumas das concepções dos ideólogos, mas não de todas elas. Não se pode, a rigor, inclui-lo nesse grupo. Entretanto, pode ser que, em sua própria época, as semelhanças entre seu discurso metodológico e o dos idéologues fossem mais evidentes do que as diferenças, e que ele pudesse ser visto como pertencente a esse grupo.

Pode-se dizer que havia, na época de Lamarck, uma certa unanimidade acerca dos limites e as possibilidades da ciência. É em relação a essa concepção empirista de ciência que os seus coetâneos poderiam julgar o seu trabalho.

Vejamos, no entanto, até que ponto a praxis de Lamarck respeita esse modelo empirista.

\section{A prática metodológica de Lamarck}

\section{Exemplos de fatos positivos citados por Lamarck}

Lamarck (1835-1845, v.1, p.48) considera, por exemplo, fatos positivos os seres vivos terem o mesmo tipo de origem, possuirem limites para a sua existência e necessidades a serem satisfeitas para a conservação da vida. Ele também considera a progressão encontrada na composição da organização dos seres vivos um fato positivo (1873, v.2, p.118; 1835-1845, v.1, p.111). É nesta perspectiva que se pode considerar que Lamarck procura fundamentar, com uma enorme massa de fatos, a existência de uma progressão dos animais. E nesse sentido ele está seguindo Condillac, procurando fundamentar a ciência da natureza - a física - com fatos obtidos pela observação (ver "Essai sur l'origine des connaissances humaines" e "Traité des systèmes", in Condillac, 1947-1951). Essa progressão, é verdade, é apenas um dos elementos de seu trabalho, mas ela é fundamental dentro de seu argumento geral:

Estabelecerei, na segunda [parte da Introdução desta obra] a existência de uma progressão na composição da organização dos diferentes animais, assim como no número e importância das faculdades que eles obtêm dela. Esse fato, estabelecido a partir da observação, tornar-se-á decisivo a favor da teoria proposta. (Lamarck, 1835-1845, v.1, p.31)

O que Lamarck realiza nos vários volumes da Histoire naturelle des animaux sans vertèbres é uma comparação sistemática dos invertebrados, classificando-os e procurando mostrar que eles podem ser agrupados em conjuntos progressivamente 
mais perfeitos. Esse trabalho por ele desenvolvido segue um modelo empirista, caracterizando-se pela coleta e comparação de um enorme volume de dados observacionais. É claro que a progressão que ele pode estabelecer com base na observação é apenas a existência de uma cadeia de perfeição entre os animais conhecidos, mas não uma progressão cronológica. Ou seja: essa de seu trabalho não permite mostrar que, ao longo do tempo, os invertebrados foram surgindo em uma seqüência progressiva de perfeição, mas permite mostrar que existe uma seqüência quase contínua de perfeição nos invertebrados conhecidos atualmente. Pode-se dizer que, nessa parte de sua obra, Lamarck está se atendo de modo bastante rígido aos "fatos positivos" e seguindo uma metodologia empirista.

Em outros casos, no entanto, poderíamos duvidar que ele estivesse empregando corretamente a distinção entre fato e teoria. Referindo-se a um fato positivo, escreve:

Seja como for, o fato positivo, ${ }^{12}$ é que, em um grande número de animais, há um calórico expansivo continuamente produzido em seu interior e é esse fluido invisivel e penetrante que aí mantém o orgasmo e a irnitabilidade de suas partes leves, enquanto que nos outros animais 0 orgasmo e a irritabilidade são principalmente o resultado do calónico dos meios ambientes. Recusar a reconhecer o orgasmo de que acabo de falar e encará-lo como um fato suposto, quer dizer como um produto da imaginação, isso seria negar nos animais a existência do tônus que as partes dos corpos possuem durante a duração de sua vida. Ora, somente a morte aniquila esse tônus, assim como o orgasmo que o constituia. (1873, v.2, p.34)

É interessante este exemplo. A irritabilidade e o tônus dos animais são observáveis diretamente. O "orgasmo", ${ }^{13}$ segundo as concepções de Lamarck, é a causa desses fenômenos e, embora não seja observável diretamente, ele o considera tão bem estabelecido quanto os próprios efeitos. Aqui, ele parece estar utilizando o seguinte tipo de raciocínio: não existem efeitos sem causa; se existe a irritabilidade, sua causa está presente; e esta causa é, exatamente, o orgasmo vital. Portanto, se a irritabilidade não pode ser negada, o orgasmo também não pode sê-lo. Assim, com certa boa vontade, pode-se ainda aqui aceitar a terminologia utilizada por Lamarck.

\section{Utilização de suposições sobre aspectos não observáveis}

Em outros pontos, Lamarck parece confundir definitivamente o domínio da certeza com o domínio da opinião. Na Philosophie zoologique ele afirma que

uma quantidade de fatos conhecidos prova que o emprego mantido de um órgão concorre para o seu desenvolvimento, fortifica-o, ou mesmo o aumenta, enquanto que a falta de emprego, tor-

\footnotetext{
12 Nas citações, os termos em itálico foram destacados pelo próprio autor, enquanto os termos em negrito foram destacados pelos presentes comentadores.

13 Lamarck fala sobre o "orgasmo vital" em várias de suas obras. Ver, por exemplo, 1986, p.61-4; 1984, p.221-7 e 1835-1845, v.1, p.90-109.
} 
nada habitual em relação a um órgão, deteriora-o, reduzindo-o gradualmente, e acaba por fazê-lo desaparecer, se a falta de emprego subsiste, durante uma longo tempo em todos os indivíduos que se sucedem pela geração... (1907a, v.1, p.259-60)

Todos sabemos que não existia essa prova da herança de caracteres adquiridos por uso e desuso.

Um segundo exemplo: refletindo sobre o poder do movimento dos fluidos nas partes macias que os contêm, Lamarck convenceu-se de que à medida que esses fluidos recebem aceleração em seu movimento, eles modificam o tecido celular no qual se movem, abrindo passagens, formando canais diversos - criando, enfim, diferentes órgãos, conforme o estado de organização em que se encontram; e transforma essa crença em certeza:

A partir dessas duas considerações, considero como certo que o movimento dos fluidos no interior dos animais, movimento que se acelerou progressivamente com a maior composição de organização, e que a influência das circunstâncias novas, à medida que os animais a ela se expuserem ao se espalharem por todos os lugares habitáveis, foram as duas causas gerais que levaram os diversos animais ao estado em que os encontramos atualmente. (p.xiv-xv)

No caso anterior, pode-se dizer que Lamarck parte da observação e de grande quantidade de fatos conhecidos no caso do "uso e desuso". Na verdade, o que ele consegue estabelecer é uma analogia entre o estado em que um órgão se encontra e o seu emprego. Entretanto, essa é apenas uma possibilidade. Lamarck não levanta outras ou mesmo tenta verificar se existem evidências contrárias a ela. Em relação à influência da circunstâncias, apresenta exemplos que a corroboram fortemente mas, mesmo assim, colocar isso como certo é problemático. Mas, de qualquer forma, ele está aqui no domínio dos "fatos positivos", sujeitos à observação e à experimentação. O mesmo não ocorre no segundo caso. Considerar certo que a aceleração do movimento dos fluidos foi a causa que levou ao estado em que os animais se encontram atualmente constitui um problema, pois não se pode nem observar esses "fluidos", nem sua aceleração, nem seu efeito nos tecidos animais - ou seja, isto está além de toda a observação e experimentação, e fora, portanto, do domínio dos "fatos positivos". Assim, isso poderia ser colocado na forma de uma possibilidade. Neste caso, o termo metacientífico "certo" indica um descuido de Lamarck. Ele está violando a distinção que ele próprio estabeleceu, entre o que é seguro e o que é apenas plausível; está violando o seu discurso metodológico, bem como o de Condillac, pois está considerando certo o que é uma mera possibilidade, e adotando uma posição favorável às suposições feitas, o que, de acordo com Condillac, deve ser evitado (ver, "Traité des systèmes", in Condillac, 1947-1951, v.1, p.203).

É importante assinalar que o próprio Lamarck percebe a existência de limitações para o conhecimento do interior mais íntimo dos seres vivos. Ao discutir a diferença entre corpos vivos e inanimados, depois de estabelecer certas características gerais, ele supõe que os seres vivos possuem uma estrutura especial, que lhes permite o desenvolvimento de fenômenos como o crescimento etc.; mas adverte: 
Esse estado das partes, que torna possível em um corpo a execução dos movimentos vitais, é tão pouco determinável que o homem não conseguiria imitá-lo. A análise e a síntese destroem e reproduzem à vontade muitos corpos ou matéria inorgânicas; mas é impossivel para o homem formar um corpo vivo, ou uma só de suas partes (1835-1845, v.1, p.61)

Aqui, portanto, Lamarck percebe o limite do conhecimento humano sobre aquilo que não se pode observar: a estrutura mais íntima da matéria.

\section{As incertezas no estudo do processo natural}

Apesar de exemplos, como o citado anteriormente, estarem presentes na obra de Lamarck, em certos casos ele percebe claramente que está no domínio teórico; por exemplo: ao discutir a seqüência de surgimento dos diferentes grupos de animais e suas crescentes complexidades. Por um lado, por comparações entre diferentes classes de animais, ele havia estabelecido distinções sob o ponto de vista de diversos sistemas ou órgãos; mas quais animais vieram antes, quais depois?

Creio estar fundamentado em concluir dessas considerações que a formação do sistema muscular é posterior àquela do sistema nervoso considerado em sua composição mais simples, mas que a faculdade de executar ações e locomoções através de órgãos musculares é, nos animais, anterior àquela de experimentar sensações. (1873, v.2, p.131-2)

A terminologia utilizada mostra uma dúvida, uma incerteza sobre a ordem seguida pela natureza ao longo do tempo. Na Histoire naturelle, Lamarck indica claramente essa incerteza geral:

Assim, os animais, como todos os outros corpos naturais, devem à natureza tudo o que eles são, todas as faculdades que possuem. É daí que partirei para desenvolver minhas pesquisas sobre os meios que ela pode ter empregado para executar, sobre esses seres, aquilo que a observação nos mostra neles. Mas nossas determinações dos próprios meios que a natureza emprega não são sempre tão positivas quanto a proposição que lhe atribui o poder de executar tantas coisas diversas. (1835-1845, v.1, p.139)

Seria seguro ou "positivo", portanto, que a natureza teria desenvolvido todas as faculdades dos animais, mas o modo exato pelo qual ela agiu não pode ser assegurado. Apesar disso, a pesquisa desses meios e a sugestão de caminhos possíveis é válida, para Lamarck, pois os caminhos efetivamente seguidos pela natureza não podem ser muito diferentes dos sugeridos:

Realmente, faltam-nos os meios para nos assegurarmos dos fundamentos de nossas determinações com relação a isso; no entanto, como nosso princípio ou nosso ponto de partida é seguro, e como ele nos pres creve limitarmos nossas idéias apenas ao campo cujos limites ele nos traça, não é necessário mais do que mostrar que as coisas poderiam ser como vou apresentá-las, e que, se forem diferentes, terão ocorrido por caminhos análogos. (Ibidem) 
Ou seja: dado o princípio de que tudo se desenvolveu pelo poder da natureza (sem causas sobrenaturais), pode-se, dentro desses limites, procurar descobrir como as coisas poderiam ter ocorrido; isso não conduzirá a certezas, mas apenas a possibilidades - e a verdade não será muito diferente dessas possibilidades entrevistas.

Pode-se ver o reflexo dessa atitude bastante cuidadosa e razoável de Lamarck em diversos trechos de sua obra:

Continuando a consultar as probabilidades sobre origem dos diferentes animais, não se pode duvidar que os répteis, por dois ramos distintos aos quais as circunstâncias levaram, originaram, por um lado, a formação dos pássaros, e pelo outro, a dos mamíferos anfíbios, os quais, originaram, por sua vez, todos os mamiferos. (1873, v.2, p.420)

Em muitos pontos como este, Lamarck é bastante cuidadoso, empregando termos como "creio estar fundamentado", "parece", "probabilidade". Mas na última citação, nota-se uma ambivalência dos termos usados: "continuando a consultar as probabilidades ... não se pode duvidar". Mesmo quando seu conhecimento epistemológico lhe diz que não pode estar seguro sobre suas concepções, Lamarck parece ser levado a uma certeza psicológica que supera seus cuidados.

Ele próprio reconhece isso, no trecho abaixo, no qual admite que, mesmo quando se afasta dos puros fatos, a "força das coisas" (termo grifado por ele próprio) o obriga a admitir certas conclusões:

Talvez me objetem que aquilo que me parece tão justo, tão fundamentado, não é senão o produto de meu julgamento, de acordo com a soma de meus conhecimentos; poder-se-á mesmo adicionar que aquilo que é o resultado de nossos julgamentos está sempre muito arriscado e que só são realmente seguros para nós os fatos constatados pela observação.

A isso, responderei que essas considerações filosóficas, geralmente muito justas, possuem no entanto seus limites e mesmo suas exceções, como muitas outras.

Sem dúvida, nossos julgamentos são muito arriscados; pois, embora estejam sempre relacionados com os elementos que neles fazemos entrar - e, sob esse ponto de vista, raramente deixam de ser justos - quase nunca temos a certeza de haver empregado em cada uma dessas operações de nossa inteligência a natureza e a totalidade dos elementos que seria necessário introduzir nelas.

No entanto, existem casos em que nossos julgamentos não são apenas o resultado de nossa maneira de considerar os fatos observados; pois eles podem também ser o resultado da força das coisas que nos arrasta contra nossa vontade, ao considerar esses fatos, sobretudo se soubemos reuni-los. Ora, essa força das coisas que nos domina quando chegamos a senti-la é um poder ao qual não se dá muita atenção e que cria exceções às considerações demasiado gerais citadas acima. Assim, há casos nos quais nossas consequiências são obrigatórias e não permitem nada de arbitrário. (1835-1845, v.1, p.3-4)

Lamarck explica, em seguida, que a "força das coisas" o levou, gradualmente, a desenvolver sua teoria. Essa é uma argumentação mais psicológica do que epistemológica. Lamarck está dizendo, com outras palavras, que não consegue pensar em uma alternativa. Mas não pode afirmar que não existe uma alternativa, pois sempre é possivel formular diferentes hipóteses que expliquem um mesmo conjunto de fatos. 
Assim, é apenas em um sentido psicológico que ele pode afirmar essa sua certeza, a falta de arbitrariedade de suas concepções e a impossibilidade de uma teoria alternativa, que ele afirma na seguinte citação:

Esta teoria ... é fundamentada? Sem dúvida, ela me parece sê-lo, pois eu a publico, e minhas observações parecem sempre confirmá-la. Se julgarem o oposto, provavelmente esforçar-se-ão por substitui-la por uma outra que seja igualmente geral e que tenha o objetivo de concordar ainda melhor com todos os fatos observados; o que não creio ser possível. (p.3)

Pode-se, assim, notar uma dualidade no pensamento de Lamarck. Por um lado, ele está bem consciente das limitações do conhecimento científico, percebendo que, ao se afastar dos fatos observáveis, entra em um domínio de conjeturas e probabilidades; por outro lado, vê-se "forçado" a admitir como verdade sua teoria, e não acredita que ela possa vir a ser substituída por melhor, o que é injustificável e incompatível com suas próprias concepções epistemológicas.

\section{Avaliações da obra de Lamarck}

Como se sabe, a teoria de Lamarck teve um baixo impacto e uma mínima aceitação em sua época, sendo considerada especulativa. Essa é a opinião de cientistas coetâneos, tais como Georges Cuvier, por exemplo, que critica a sua teoria "evolucionista" em vários de seus trabalhos. ${ }^{14}$

Cuvier diferencia duas partes da obra de Lamarck: uma, "positiva", de real valor; e outra, especulativa, "sistemática", sem valor nenhum:

Seja como for, o Sr. Lamarck reproduziu essa teoria da vida em toda as obras zoológicas que seguiram as Recherches; e qualquer que fosse o interesse que essas obras suscitassem por suas partes positivas, ninguém achou sua parte sistemática tão perigosa a ponto de merecer ser atacada; ela foi deixada na mesma paz que sua teoria química, e pela mesma razão: é que cada um pode perceber que, independentemente de muitos paralogismos de detalhe, ela repousa também sobre suposições arbitrárias: uma, que é o vapor seminal que organiza o embrião; a outra, que desejos e esforços podem engendrar órgãos. Um sistema apoiado em tais bases pode divertir a imaginação de um poeta; um metafísico pode derivar daí uma geração totalmente diferente de sistemas; mas não pode suportar por um momento o exame de alguém que já dissecou uma mão, uma víscera, ou somente uma pena. (1835, p.xx-xxi)

Esta é, claramente, uma crítica que se baseia em uma visão empirista da ciência.

14 Ver, por exemplo, Cuvier, 1810, p.234-5; o discurso preliminar da obra de Cuvier (1812, v.1, p.28 e 1825), em que o autor compara Lamarck aos autores que propuseram doutrinas "fantásticas", tais como Robinet e De Maillet. Ver também o Éloge que Cuvier fez por ocasião da morte de Lamarck, em que afirma que a sua obra, a partir das Recherches sur l'organisation des corps vivants, repousa sobre suposições arbitrárias (1835, p.ii-iii). 
Outro coetâneo de Lamarck, Sonnini de Manoncourt, considera as Recherches um amontoado de meditações (ver Corsi, 1989, p.170). Autores posteriores a Lamarck, como Quatrefages (1870, p.71), por exemplo, apesar de avaliarem positivamente algumas de suas contribuições, consideram certos aspectos de sua teoria especulativos, nos quais ele toma a possibilidade como prova e o desconhecido como argumento. Esta também é a visão de Louis Trenchard More (1925, p.163, 166).

Essa visão é também partilhada por alguns historiadores atuais da ciência como, por exemplo, Richard W. Burkhardt, que afirma que o trabalho de Lamarck apresenta ambigüidades, inconsistências e que ele era um especulador numa época em que uma forte metodologia empírica dominava as ciências naturais na França (1977, p.144, 218; ver também a introdução à Zoological Philosophy, Lamarck, 1984, p.xvi). Outro historiador, Louis N. Magner (1979, p.354), inclui Lamarck na "especulação evolucionária", juntamente com Benoît de Maillet, Maupertuis e Buffon. Mais para a frente, ele escreve que Lamarck pode ser considerado o protótipo do cientista estúpido (crackpot) com interesses excênticos, muitas vezes beirando a loucura (p.363).

Há, entretanto, um historiador da ciência que desenvolveu uma elaborada defesa da obra de Lamarck: Léon Szyfman. É relevante discutir um pouco a sua interpretação, por se tratar do único historiador da ciência que discutiu mais detalhadamente a metodologia de Lamarck.

Szyfman nega a validade de analisar a obra de Lamarck sob o ponto de vista empirista. Ele afirma não só que sua metodologia difere daquela de Condillac, como defende ser ele criador de uma nova metodologia (1982, p.266-7). Segundo Szyfman (1971, p.243), os sábios da época não estavam preparados nem filosofica nem cientificamente para conceber a idéia genial de Lamarck. Afirma que Lamarck pretendia fundar uma teoria geral que abrangesse as leis comuns a todos os domínios de que se ocupa o espírito humano ${ }^{15}$ e que existe uma coerência entre os primeiros enunciados metodológicos de 1800, ou seja, seu Discours du cours de zoologie, e aqueles formulados nas obras ulteriores (p.244-5).

Szyfman assim caracteriza a metodologia de Lamarck:

A característica da metologia de Lamarck é a unidade de observação e a reflexão intelectual. Esse princípio metodológico é desenvolvido em um grau maior por Haeckel. Mas a originalidade do sistema metodológico de Lamarck consiste não somente na unidade do empirismo e da reflexão, atitude que já encontramos antes de Lamarck. O que distingue o fundador do evolucionismo de seus precursores se desvela em seu método histórico de diversas formas: na geologia sob a forma atualista e comparativa, em biologia como um evolucionismo universal e progressivo e em psicologia e psicofisiologia sob a forma histórica e comparativa. (p.246)

Aqui, evidentemente, o historiador está confundindo teoria com método: o evolucionismo, por exemplo, não é um método, e sim um aspecto da teoria da Lamarck. Em que consistiria esse "método histórico" de Lamarck? Alguém poderia estudar o

15 É evidente o exagero dessa afirmação. 
desenvolvimento da crosta terrestre, na época de Lamarck, sem considerar a história da Terra?

Continuando, Szyfman caracteriza o método empregado por Lamarck: "Assim vemos que a metodologia de Lamarck se caracteriza por um lado pela unidade do empirismo e da reflexão, por outro lado pelo historicismo progressivo e o atualismo retrospectivo" (p.246).

Para Szyfman (p.252-3), Lamarck ataca o método indutivo de Condillac quando critica os sábios que "se comprazem na consideração de objetos minuciosos", porque este método leva o pesquisador a um impasse. Para Lamarck, a confusão que reinava nas ciências naturais a partir do século XIX exigia a criação de um método e de uma teoria novos.

Apesar dessa opinião de Szyfman, em nenhum instante, na própria obra de Lamarck, encontra-se uma afirmação de que ele se considera o criador de um novo método.

Em relação ao método de Condillac, Szyfman, afirma:

O brilhante renome de Condillac foi firmado no fim do século XVIII e início do século XIX, sobretudo pelo transporte do empirismo de Locke para o solo francês. Partindo da análise crítica do sensualismo proposta pelo filósofo inglês, ele substitui a sensação e a reflexão por uma única fonte de conhecimento: a sensação. ${ }^{16} \mathrm{O}$ método de Condillac respondia efetivamente às necessidades das ciências naturais e de sua prática, porque ele era analítico. As idéias de Condillac fecundavam escolas científicas e filosóficas opostas. Guyton de Morveau, Bertholet, Fourcroy, Vicq d'Azyr, eis aí alguns discípulos de Condillac. Pinel, Diderot, D'Alembert, Helvetius, Volney, Lakanal, Destutt de Tracy estudaram e aplicaram o método de Condillac. Esse método se caracteriza pela observação dos fenômenos, pela análise, pela descoberta das relações quantitativas entre os fatos, pelo estabelecimento de hipóteses confirmadas pelos fatos e, enfim, pela descoberta das leis gerais. Não seria de se admirar se ele fascinasse os naturalistas e humanistas esclarecidos, ainda mais que era formulado em uma linguagem elegante, clara e sugestiva. (p.253-4)

Conforme Szyfman (p.255-6), embora Lamarck fosse partidário dos preceitos acima, ele achava que o poder analítico do método de Condillac era muito exagerado. Condillac era contra os ensaios de síntese como primeiro passo da pesquisa e, segundo Szyfman, é por eles que Lamarck recomenda que se inicie. Lamarck postula que um ensinamento bem feito deve começar pela apresentação da teoria em seu conjunto e em suas linhas gerais, sem entrar em nenhum detalhe preliminar. Para ele, o método de investigação difere do método de exposição.

É preciso distinguir método de pesquisa de método de exposição; não há conflito algum aqui entre Condillac e Lamarck.

Szyfman resume a metodologia de Lamarck:

Passagens das grandes generalizações às pesquisas concretas, descoberta de leis particulares e gerais, verificação dos conceitos abstratos com a ajuda de estudos laboriosos e a com-

16 Isto é totalmente falso. 
prensão da verdade de cuja reunião de fatos não constitui ainda a ciência, pois esta se elabora pelo conhecimento de leis e relações essenciais da realidade. Enfim, conforme Lamarck, a dedução e a indução constituem apenas procedimentos auxiliares de um método mais geral que deve ser evolucionista. (p.256)

Não se sabe o que Szyfman quer dizer com "método evolucionista". Lamarck jamais fala sobre isso. Por outro lado, os aspectos aqui enfatizados por Szyfman como representando a metodologia de Lamarck concordam com a descrição que o próprio historiador faz da metodologia preconizada por Condillac.

O próprio Lamarck escreve a respeito:

Ao vos dedicar ao estudo da natureza e de suas produções, examinai primeiro em seu conjunto os objetos propostos para o conhecimento; considerai bem esse conjunto sob diversos pontos de vista afim de penetrar o suficiente no assunto de vossa empreitada e na intenção mantida; e a seguir deçais por degraus no exame e estudo das massas, começando pelas maiores ou aquelas da primeira ordem, em vos ocupando daquelas que vos são subordinadas. Terminareis, se tiverdes o vagar, pelos estudos dos objetos particulares, tais como das raças ou espécies, o estudo dos caracteres distintivos, bem como todos os caracteres particulares que elas possam vos oferecer. Enfim, vós vos instruireis se isso vos interessar, a respeito dos nomes que lhes foram dados; mas não confundireis jamais a seu respeito o que pertence à natureza com o que é produto da arte. Tal é a marcha do método de análise, tão bem desenvolvido por Condillac; e o único verdadeiramente favorável aos progressos de nossos conhecimentos.

Esse será o método de análise que seguiremos nesse curso, onde passaremos sucessivamente em revista todas as classes dos animais sem vértebras, ocupando-nos principalmente em toda a parte da filosofia da ciência, assim como dos objetos essenciais ao conhecimento dos animais que teremos em vista. (1907b, p.562)

Em vez de criticar Condillac, Lamarck diz estar seguindo seu método. Pode-se ver que é bastante problemática a opinião de Szyfman sobre o método de Lamarck. Lamarck defende, indubitavelmente, em seu discurso metodológico, uma abordagem semelhante à de Condillac.

\section{A concepção de natureza de Lamarck como delimitadora da ciência}

Se analisarmos apenas esses aspectos, a obra de Lamarck poderia se afigurar como desprovida de fundamento, pois, de acordo com o discurso metodológico adotado por ele próprio, sua prática é insatisfatória. No entanto, é preciso analisar outros aspectos do trabalho de Lamarck.

Existe um ponto importante a ser considerado: a sua teoria da progressão dos animais é parte de uma teoria mais ampla. Talvez alguns pontos da teoria menor não precisassem ser fundamentados empiricamente, caso essa teoria mais ampla fosse levada em conta.

Pode-se dizer que, nesse sentido, algumas partes da teoria de Lamarck adquirem um outro aspecto e talvez se possa admitir que não precisariam receber apoio empí- 
rico direto, como o que tem sido buscado pelos analistas da obra de Lamarck. Há certos princípios muito gerais, aceitos por Lamarck como ponto de partida de seu trabalho, que delimitam o tipo de teoria que ele admite - não sob o ponto de vista metodológico, mas sob o ponto de vista ontológico ou metafísico.

Lamarck estabelece na introdução da Histoire naturelle des animaux sans vertèbres as condiçđ̃es gerais que deve preencher uma teoria sobre os seres vivos, com base em sua concepção sobre a natureza. Essas condições não representam fatos, e sim exigências pré-teóricas sobre o que é admissível ou não. Lamarck afirma claramente que esses princípios delimitam a pesquisa, eliminando a sua arbitrariedade:

Aqui, eu deveria esclarecer todas essas considerações, mostrar a inconveniência dos preceitos admitidos e provar que em relação ao que queremos colocar em seu lugar, não se trata de hipóteses novas, mas verdades claras, evidentes, sobre as quais as observações não nos autorizam a menor dúvida, quando se quer examiná-las.

No entanto, é importante, antes de tudo, apresentar os princípios fundamentais seguintes, a fim de impedir qualquer arbítrio nas conseqüências que podem ser tiradas dos fatos conhecidos: Principios fundamentais

$1{ }^{\circ}$ Princípio: Todo fato ou fenômeno que pode ser conhecido pela observação é essenciamente físico, e sua existência só é devida a corpos ou às relações entre os corpos.

2 ํ Princípio: Todo movimento ou mudança, toda força que age e todo e qualquer efeito, observados em um corpo, procedem necessariamente de causas mecânicas, regidas por leis.

3ำ Princípio: Todo fato ou fenômeno observado em um corpo vivo é ao mesmo tempo um fato ou fenômeno físico, e um produto de sua organização.

... Sem esses princípios, que estão a salvo de toda contestação sólida, a zoologia seria desprovida de fundamento. (1835-1845, v.1, p.19-20)

Esses princípios não pertencem nem à teoria da progressão dos animais, nem à zoologia, nem à biologia, mas são princípios totalmente gerais, que - segundo Lamarck - devem fazer parte de todo estudo "físico", ou seja, de todo estudo da natureza. Trata-se de um "credo" materialista, fisicalista (e, especificamente, mecanicista) que não pode ser demonstrado pelos fatos (pois precede o próprio estudo dos fatos), mas que deve guiar o seu estudo:

reconhecer-se-á facilmente que os diferentes fenômenos que nos são oferecidos pelos corpos vivos são todos verdadeiramente físicos; que suas próprias causas são determináveis, embora difíceis de captar... (p.60)

Seria admissível, para Lamarck, explicar os fatos naturais pela intervenção divina? Não. Para ele, isso seria fugir à "física", que é o estudo da natureza. Deus pode ter criado a natureza; mas o estudo da natureza não inclui o estudo de Deus.

Assim, como naturalista e como físico, só devo me ocupar, em meus estudos da natureza, dos corpos que conhecemos e que foram observados, das qualidades e das propriedades desses corpos, das relações que eles podem ter uns com os outros em diferentes circunstâncias, enfim, das seqüências dessas relações e dos diversos movimentos espalhados e continuamente mantidos entre eles. 
Por esse caminho, o único que está à nossa disposição, torna-se possível entrever as causas dessa multidão de fenômenos que nos oferece a natureza em suas diversas partes e até mesmo perceber as dos fenômenos admiráveis que nos são apresentados pelos corpos vivos. (1970a, v.1, p.351)

Lamarck apresenta em diversos pontos de suas obras um conceito de "natureza" :17

A Natureza, essa palavra tão freqüentemente pronunciada como se fosse um ser particular, não deve ser a nossos olhos mais do que o conjunto de objetos que compreende: $1^{\circ}$ todos os corpos físicos que existem; $2^{\circ}$ as leis gerais e particulares que regem as mudanças de estado e de situação que esses corpos podem sofrer; $3^{\circ}$ enfim, o movimento espalhado de diversas formas entre eles, perpetuamente mantido ou renascendo de sua fonte, infinitamente variado em seus produtos e de onde resulta a ordem admirável das coisas que esse conjunto nos apresenta. (p.349)

No Système analytique, Lamarck esclarece, igualmente, que a natureza não é uma inteligência, não é um ser, mas uma ordem de coisas, estando totalmente sujeita a leis (1820, p.43).

Os fenômenos naturais devem ser explicados apenas pelas leis da natureza. Isso impõe restrições sobre a sua teoria dos animais. Se tudo deve ser compreendido de acordo com as forças da natureza, não se pode pensar em uma criação dos seres vivos por milagre divino.

A organização e a vida são o produto da natureza e ao mesmo tempo o resultado dos meios que ela recebeu do Autor supremo ${ }^{18}$ de todas as coisas e das leis que constituem sua própria essência: não poderiamos duvidar hoje disso. Assim, a organização e a vida não passam de fenômenos naturais... $(1873, \mathrm{v} .2, \mathrm{p} .57)$

... a natureza [é] o poder, de certa forma mecânico, que deu existência aos diversos animais e que os fez necessariamente aquilo que são. (1835-1845, v.1, p.31)

Pode parecer óbvio que os seres naturais devem ser estudados apenas dentro do contexto da própria natureza; mas isso não era feito, na época de Lamarck, para os seres vivos. Por exemplo, Georges Cuvier acreditava que as espécies haviam sido criadas por Deus (ver Marchant, 1858, p.178). Outro coetâneo de Lamarck, Jean Joseph Virey (1803, p.347), embora partilhasse de várias de suas idéias evolucionistas, considera a natureza resultante da ação de um ser supremo que dirige e causa toda mudança. Virey acredita ainda que é impossivel imaginar a organização dos animais e plantas sem pensar em uma causa suprema infinitamente inteligente para isso (p.412). Por esse motivo, Lamarck precisa repetidamente chamar a atenção para esse ponto:

17 Ele dedica a esse tema um verbete do Nouveau dictionnaire d'histoire naturelle de Déterville, que é reproduzido no segundo capítulo de seu último livro, o Système analytique des connaissances positives de l'homme.

18 O "Autor supremo" da natureza, ou Deus, é admitido por Lamarck (1820, p.8) como existente, mas excluído da ciência. Ele afirma que a única coisa que se pode afirmar "positivamente" de Deus é que ele existe e é todopoderoso. Como ele não pode ser conhecido, deve ser excluído do estudo da natureza. 
Notemos que, embora se aceite geralmente indicar sob o nome geral de produções da natureza os seres que compõem cada reino, parece no entanto que não se associa nenhuma idéia positiva a essa expressão. Aparentemente, prevenções de uma origem particular ${ }^{19}$ impedem-nos de reconhecer que a natureza possui a faculdade e todos os meios de dar, ela própria, a existência a tantos seres diferentes, de variar incessantemente - embora muito lentamente - as raças dos que são dotados de vida, e de manter por toda parte a ordem geral que observamos. (1907a, v.1, p.68-9)

Na Histoire naturelle, falando tanto sobre os corpos vivos quanto sobre os inorgânicos, Lamarck afirma: "Uns e outros, no entanto, são verdadeiras produções da natureza: eles resultam de seus meios, dos movimentos distribuídos em suas partes, das leis que regem todos os seus gêneros; enfim, das afinidades, grandes ou pequenas, que se encontram entre as diferentes matérias que ela emprega em suas operações" (1835-1845, v.1, p.55).

Numa perspectiva puramente naturalista, se os seres vivos existem, eles seriam ou eternos ou produzidos pela própria natureza. A eternidade da natureza é rejeitada por Lamarck. Ele percebe que a natureza terrestre se transforma com o tempo. Essa idéia aparece em várias de suas obras, tais como a Hydrogeology, em que ele fala não apenas das transformações geológicas (formato, natureza, massa e localização) que ocorrem na Terra, como em todas as coisas que nela se encontram. Ele fala da grande idade da Terra, da origem dos seres vivos e de seus gradual desenvolvimento e aperfeiçoamento. Ele coloca ainda o homem como o último resultado dessa progressão, embora não se possa conhecer o final desse processo (1964, p.61-2, 77). Se a vida não é eterna, resta a única possibilidade de que a vida seja um produto das próprias forças físicas e das leis da natureza.

Como os animais são produções da natureza, é dela conseqüentemente que eles tiram sua existência e as faculdades que possuem; ela formou os mais perfeitos como os mais imperfeitos; ela produziu as diferentes organizações que são notadas entre eles; enfim, com a ajuda de cada organização e de cada sistema particular de órgãos, ela dotou os animais das diversas faculdades que conhecemos neles. Ela possui portanto os meios para produzir essas coisas...

Agora, creio poder assegurar que se foi ela que realmente fez essas mesmas coisas existirem, ela as realizou sem dúvida fisicamente; pois como seus meios são puramente físicos, não se pode atribuir-lhe outros. (1835-1845, v.1, p.140)

Por mais difícil que seja esse grande assunto de pesquisa la fonte da vida e a origem dos diferentes corpos vivos que existem], as dificuldades que ele nos apresenta não são insuperáveis, pois trata-se, em tudo isso, de fenômenos puramente físicos. (1907a, v.1, p.352)

Se os corpos vivos são corpos naturais, a natureza é capaz de produzir todos os seres vivos. Mas como terá isso acontecido? Teria ela produzido todos os seres vivos ao mesmo tempo, independentemente uns dos outros? Teria ela gerado a partir da matéria inanimada, diretamente, um pássaro, uma baleia, uma árvore? Isso não seria

19 Lamarck, cuidadosamente, não indica aqui qual a natureza dessa "prevenção" que seria, evidentemente, de origem religiosa. 
impossivel, mas seria pouco plausivel. Por um lado, não se vê, atualmente, que a natureza produza os animais a partir da matéria inanimada: eles surgem através da geração, a partir de pais.

Para que os corpos vivos sejam realmente produtos da natureza, é necessário que ela tenha possuído e que ela ainda possua a faculdade de produzir diretamente alguns deles, para que, munindo-os da [faculdade] de crescer, de se multiplicar, de compor cada vez mais sua organização e diversificá-la com o tempo e segundo as circunstâncias, todos os que observamos hoje sejam verdadeiramente produtos de seu poder e de seus meios. (p.357)

Lamarck exclui, em seguida, o leão, a águia, a borboleta, o carvalho, a roseira da possibilidade de criação direta, pois eles são gerados a partir de indivíduos semelhantes a eles; por exclusão, os criados diretamente pela natureza são os mais simples e cujo modo de reprodução não é aparente.

Lamarck adota um outro princípio geral, o de que a natureza sempre procede do mais simples ao mais composto (1820, p.135). Poderia também utilizar o antigo princípio de que "a natureza não dá saltos", mas ele aparentemente evita esse princípio, que poderia ser utilizado contra ele próprio, por não admitir uma gradação entre os três reinos da natureza.

Com efeito, se é verdade que todos os corpos vivos são produções da natureza, não podemos nos recusar a crer que ela só pôde produzi-los sucessivamente e não todos simultaneamente, em um tempo sem duração. Ora, se ela os formou sucessivamente, ocorre-nos pensar que ela começou unicamente pelos mais simples, somente tendo produzido em último lugar as organizações mais compostas - seja do reino animal, seja do reino vegetal. (1907a, v.1, p.232)

Pode-se considerar uma parte da teoria de Lamarck de um caráter dedutivo, pois ele parece tirar algumas conclusões de seus princípios gerais, de sua ontologia - e não da observação. Se os seres vivos existem e se precisam ser explicados pelos poderes naturais, é necessário admitir a possibilidade de que surjam seres vivos a partir da matéria inanimada. A única alternativa, dentro de uma visão naturalista, seria pensar na vida como algo eterno, que teria existido sempre, ao mesmo tempo que a matéria. Assim, negando-se a eternidade da vida, surge necessariamente a geração espontânea como única saída.

Como todos os corpos vivos são produções da natureza, ela própria necessariamente organizou os mais simples desses corpos, deu-lhes diretamente a vida e com ela as faculdades que são geralmente próprias aos que a possuem. Por meio dessas gerações diretas formadas no começo da escala, seja animal, seja vegetal, a natureza conseguiu progressivamente dar existência a todos os outros corpos vivos. $\left(1873\right.$, v. 2, p.428) ${ }^{20}$

Se reconhecermos que todos os corpos naturais são realmente produções da natureza, deve ser então totalmente evidente que, para dar existência aos diferentes corpos vivos, ela deve

20 Esta citação é tirada do sumário do segundo volume: cap.vi - sobre as gerações diretas ou espontâneas; no próprio texto da obra não se encontra uma formulação tão clara e sintética quanto esta. 
necessariamente ter começado por formar os mais simples de todos, quer dizer, por criar os que não são verdadeiramente mais do que esboços de organização e que apenas ousamos considerar como corpos organizados e dotados de vida. (p.63)

Assim, parece que é a partir de princípios gerais e não a partir do estudo empírico que Lamarck estabelece a necessidade de se aceitar a geração espontânea. Isso é confirmado por vários pontos de sua obra. Por exemplo: na Philosophie zoologique, depois de dar vários exemplos presumíveis de geração espontânea, incluindo vermes intestinais, cogumelos e mofo, Lamarck manifesta dúvidas sobre se realmente eles provêm diretamente da matéria inorgânica, dizendo que não tem uma opinião formada sobre isso:

Se as gerações diretas, que são o tema deste capítulo, ocorrem realmente ou não - sobre o que, atualmente, não tenho opinião determinada - é certo, penso, que a natureza as executa realmente no início de cada reino dos corpos vivos e que sem esse caminho ela jamais teria podido dar existência aos vegetais e aos animais que habitam nosso globo. (p.83)

Parece que Lamarck percebe que a evidência empírica não é muito forte; mas é certo que a natureza pode originar a vida, caso contrário a vida não existiria.

De forma análoga, admitindo-se como fato que existem os animais superiores e que eles não surgem espontaneamente, ficam também apenas duas alternativas dentro da visão naturalista: ou eles são eternos, ou surgiram por ação da natureza. Se eles surgiram pela ação da natureza, ela deve ter o poder de transformar os seres vivos è dar-lhes progressivamente uma maior complexidade e perfeição. Lamarck indica como um dos "princípios ou axiomas zoológicos":

Como a natureza, em todas suas operações, só pôde proceder gradualmente, ela não pôde produzir todos os animais ao mesmo tempo. Ela inicialmente formou apenas os mais simples, e passando desses aos mais compostos, ela estabeleceu sucessivamente neles diferentes sistemas de órgãos particulares, multiplicou-os, aumentou-lhes cada vez mais a energia e, acumulando-os nos mais perfeitos, ela fez existirem todos os animais conhecidos, com a organização e as faculdades que neles observamos. Ou ela nada fez absolutamente, ou ela of fez assim. (1835-1845, v.1, p.105)

O trecho enfatizado na citação acima mostra que Lamarck está seguro de sua posição, que não se baseia em "fatos", e sim em seus princípios.

A partir desta interpretação, a obra de Lamarck adquire um novo aspecto. Seu método efetivo de trabalho, sua praxis, está longe de ser empirista. Ele está construindo um sistema baseado em princípios a priori, contrariando todas as recomendações de Condillac e o horror que todos os "ideólogos" tinham a tais sistemas. Mas é justamente isso o que dá força e importância à sua obra. É essa nova visão da natureza e da delimitação do trabalho do naturalista que irá gradualmente se firmar, permeando a obra de Darwin e de todos os evolucionistas, até se tornar tão "natural", que nem percebemos sua importância. 


\section{Uma reconstrução do método de Lamarck}

Para defendermos essa interpretação de Lamarck, é necessário admitir, primeiramente, que Lamarck é inconsistente. Já havíamos visto que a prática de Lamarck destoa de seu discurso metodológico; é preciso admitir, além disso, que Lamarck não estava consciente de que seu trabalho científico utilizava uma metodologia nova e conflitante com o empirismo. Há, entranto, um aspecto positivo nesse conflito: não se trata de uma simples violação do empirismo, ou seja, de uma incapacidade de preencher seus requisitos. Trata-se de um outro tipo de método, baseado em princípios fundamentais, a priori, que torna desnecessário, em muitos aspectos, uma fundamentação baseada em fatos.

Certamente, os pressupostos básicos de Lamarck não estavam claros, para ele próprio, em suas primeiras obras. O "credo" fisicalista acima descrito apenas aparece em sua penúltima obra - a Histoire naturelle des animaux sans vertèbres. E mesmo então, o próprio Lamarck não deve ter percebido toda a importância desses princípios, nem que estava utilizando um método contrário ao empirismo.

A partir da análise da prática científica de Lamarck, principalmente sob a forma exibida em suas últimas obras, podemos dizer que seu método era o seguinte:

1 Por um lado, a ciência devia se basear em "fatos positivos", indubitáveis, tirados da experiência e de sua generalização.

2 Por outro lado, a ciência devia ser guiada por princípios gerais (no caso, um "credo" fisicalista) capazes de delimitar o tipo de causas que podem ser buscadas para a explicação dos fenômenos naturais.

3 A partir desses princípios gerais, devem ser procuradas explicações admissíveis dos fatos conhecidos, formando uma teoria sistemática. Essas explicações e essa teoria não serão necessariamente verdadeiras, mas constituirão uma etapa útil do progresso científico.

Os "fatos positivos" básicos da teoria evolucionista de Lamarck são muitos: a variação das condições de vida na Terra, ao longo do tempo; a adaptação quase perfeita dos seres vivos ao seu ambiente e ao seu meio de vida; a existência de uma gradação e progressão dos animais; a inexistência de seres vivos na Terra em eras anteriores; a inexistência de geração espontânea para os animais superiores; e muitos outros.

Admitindo-se o fisicalismo de Lamarck, como explicar a existência dos seres vivos conhecidos atualmente? De onde eles vieram e como se tornaram o que são?

Utilizando os conhecimentos de sua época - e complementando-os, é verdade, com bastante imaginação -, Lamarck procurou conceber processos que pudessem levar ao surgimento da vida e à sua progressão, até o desenvolvimento dos animais superiores e do homem. Não aceitamos, atualmente, as explicações e a teoria de Lamarck - mas, na sua própria época, não se podia esperar algo parecido com a teoria evolucionista atualmente aceita. No entanto, mais importante do que aquilo que foi abandonado, é aquilo que restou de Lamarck. 
Pode-se comparar esse episódio com a história da astronomia. Na época de Platão, os matemáticos gregos aceitaram que os fenômenos celestes fossem totalmente regulares, que podiam ser explicados e previstos quantitativamente, em seus mínimos detalhes - e puseram-se ao trabalho para construir uma astronomia que preenchesse esse desideratum. Nossa astronomia moderna é completamente diferente do sistema de Ptolomeu - contudo, o objetivo atual ainda é o mesmo. Antes de Lamarck, os naturalistas não tinham se colocado o objetivo de explicar a existência dos seres vivos e suas características atuais com base em leis e fenômenos puramente naturais ("físicos"). É a partir de Lamarck que esse novo desideratum passa a guiar o desenvolvimento da biologia.

\section{Considerações finais}

Este trabalho procurou mostrar que, por seu discurso metodológico, Lamarck é, sem dúvida, um seguidor de Condillac. Portanto, nesse sentido, foi um "ideólogo". Entretanto, Lamarck não partilha do empirismo mais limitado desse grupo. A idéia de ciência explicitada no seu discurso metodológico está mais próxima da idéia original de Condillac. De fato: a busca de princípios gerais e leis, bem como a construção de um sistema por Lamarck estavam de acordo com a concepção de Condillac, mas não com a dos principais "ideólogos".

A concepção dominante da época admitia a existência de limitações para a investigação humana. Dever-se-ia evitar a formulação de hipóteses sem fundamentação e restringir a ciência aos fatos. Entretanto, Lamarck se permite o uso de suposições explicativas, utilizando fenômenos inobserváveis, o que certamente seria rejeitado pelos ideólogos. Condillac admitia o uso dessas suposições ou hipóteses, desde que ficasse claro que não eram "fatos".

Quanto à sua praxis, nota-se que Lamarck algumas vezes é coerente em relação ao discurso metodológico acima, mas outras vezes não. Por exemplo, ao descrever a degradação que existe na organização e nas faculdades dos animais que constituem a escala animal, considerada em ordem decrescente de perfeição e considerando-a um fato positivo (1907b, p.566; v.2, p.118), ele está sendo coerente. Entretanto, outras vezes Lamarck parece confundir o domínio da certeza com o domínio da opinião. Tal é o caso dos movimentos dos fluidos no interior dos tecidos que vão abrindo passagens, formando canais diversos, criando novos órgãos etc. (1907a, v.1, p.xiv-xv). Lamarck, ao considerar isso certo, infringe o que ele estabeleceu, pois isso não pode ser observado.

Outras vezes, Lamarck é bastante cauteloso, seguindo o que prega seu discurso metodológico - por exemplo, ao tratar da origem dos diversos grupos de animais nas Additions da Philosophie zoologique (1873, v.2, p.423), em que ele afirma que as considerações feitas podem ser tomadas por conjecturas, mas que se for examinado o 
que a obra contém, existe uma "grande probabilidade" de que as coisas tenham se passado dessa forma. Ele também coloca que uma dificuldade em aceitar as mudanças ocorridas que diversificaram os animais é que o homem não as testemunhou (p.425).

Assim, pode-se dizer que, às vezes, Lamarck é coerente com o seu discurso metodológico. Outras vezes, parece que sua certeza psicológica o supera.

Caso se avalie a teoria da progressão dos animais de Lamarck com base em um contexto empirista, verificar-se-á muitas vezes a existência de um conflito entre discurso metodológico e prática, como é o caso da explicação para a origem dos primeiros seres vivos, como daqueles mais simples, por meio da geração espontânea. Ela não é decorrente de um estudo empírico e sim de princípios que fazem parte de um credo materialista, fisicalista, mecanicista de Lamarck. Partindo-se desse credo, a posição de Lamarck é compreensível e aceitável. A dificuldade é que ele não defende, em seu discurso metodológico, uma teoria baseada em princípios abstratos. Ele recai em um tipo de sistema altamente combatido por Condillac, ou mesmo pelos "ideólogos" (ver "Traité des systèmes" in Condillac 1947-1951, p.121; e Picavet, 1891).

Talvez o próprio Lamarck não tenha percebido que estava desenvolvendo um trabalho que exigia um novo tipo de metodologia. Se ele próprio tivesse sido capaz de explicitar sua divergência em relação às concepções empiristas, ficaria claro, em sua própria época, que ele não poderia ser avaliado unicamente a partir das evidências empíricas apresentadas, e sim a partir de seus pressupostos metafísicos. E isso, exatamente, é o que o presente artigo propõe. Se admitirmos os pressupostos básicos que Lamarck apresenta, suas conclusões gerais (a origem da vida e sua evolução) se tornam necessárias. Mesmo que o mecanismo ou processo de evolução proposto por ele possa ser colocado em dúvida (pois se trata de uma possibilidade entre muitas), a sua visão mais ampla repousa sobre uma base que, hoje em dia, é aceita pela maior parte dos naturalistas, e que possibilitou o desenvolvimento posterior da biologia, tal como a conhecemos.

\section{Agradecimentos}

Os autores agradecem o apoio recebido da Fapesp e ao CNPq, sem os quais teria sido impossivel a realização deste trabalho. 
MARTINS, L. Al-C. P., MARTINS, R. de A. Lamarck's method. Trans/Form/Ação (São Paulo), V.19, p.115-140, 1996.

- ABSTRACT: This paper studies Lamarck's scientific method both from the point of view of his methodological discourse and according to his scientific praxis. Lamarck's methodology is compared to Condillac's as well as to that of the idéologues - a group in which Lamarck is usually included. The analysis of this paper shows that Lamarck's methodological discourse is very similar to Condillac's, but his scientific praxis does not follow this view. Instead of following an empinicist approach, Lamarck's work is grounded upon general metaphysical principles concerning nature. Thus, from the idéologues's point of view, Lamarck's work should have been rejected - and that is what really happened - as being a mere metaphysical system (système) - in the pejorative sense employed by Condillac's followers. However, the present work argues that this is in fact an important and innovative aspect of Lamarck's work and that it lead to the emergence of modern evolutionism.

- KEYWORDS: Lamarck; Condillac; empinism; scientific method; evolution; French philosophy - 19th. century; idéologues.

\section{Referências bibliográficas}

BUFFON, G. L. L., conde. Oeuvres philosophiques de Buffon. Ed. Jean Piveateau. Paris: Presses Universitaires de France, 1954.

BURKHARDT, R. W. The Spirit of System; Lamarck and Evolutionary Biology. Cambridge, MA: Harvard University, 1977.

CABANIS, P. J. G. Du degré de certitude de la médicine. Paris: Crapelet, an XI [1803].

CONDILlAC, É. B., abbé de. Oeuvres philosophiques de Condillac. Ed. G. le Roy. Paris: Presses Universitaires de France, 1947-1951. 3v.

CORSI, P. The Age of Lamarck. Evolutionary Theories in France: 1790-1830. Trad. J. Mandelbaum. Berkeley: University of California, 1989.

CUVIER, G. D. Rapport historique sur le progrès des sciences naturelles depuis 1789 et sur leur état actuel. Paris: Imprimérie Impériale, 1810.

Recherches sur les ossements fossiles des quadrupèdes où l'on rétablit les caractères de plusieurs espèces d'animaux que les révolutions du globe paroissent avoir détruites. Paris: Déterville, 1812. v.1

Discours sur les révolutions du globe, et sur les changements qu'elles on produits dans le règne animal. Paris: Dufour et d'Ocagne, 1825.

Éloge de M. de Lamarck, lu à l'Académie royale des sciences le 26 Novembre 1832. Mémoires de l'Académie des Sciences de l'Institut de France, v.13, p.i-xxxi, 1835.

D'ALEMBERT, J. le R. Discours préliminaire de l'Encyclopédie. Paris: Debuisson, 1864.

LAMARCK, J. B. Histoire naturelle des animaux sans vertèbres. 2.ed. Paris: Verdière, 18151822.

Système analytique des connaissances positives de l'homme. Paris: Chez l'Auteur,

au Jardin du Roi, 1820.

Histoire naturelle des animaux sans vertèbres. 2.ed. révue et augmenté de notes présentant les faits nouveaux dont la science s'est enrichie jusqu'à ce jour, par M. M. G. H. Deshayes et H. Milne-Edwards. Paris: Baillière, 1835-1845. 11v. 
LAMARCK, J. B. Philosophie zoologique. Paris: Libraire F. Savy, 1873. v.2. Philosophie zoologique. Paris: Libraire Schleicher Frères, 1907a. v.1

Discours d'ouverture des cours de Zoologie donnés dans le Muséum d'Histoire naturelle (an VIII, an X, an XI et 1806). Ed. A. Giard. Bulletin Scientifique de la France et de la Belgique [Série 5], v.40, p 443-595, 1907b.

Hydrogeology. Trad. A. V. Carozzi. Urbana: University of Illinois, 1964.

Zoological Philosophy. Trad. H. Elliot. Chicago: The University of Chicago, 1984.

Recherches sur l'organisation des corps vivants. Paris: Fayard, 1986.

LANDRIEU, M. Lamarck, le fondateur du transformisme: sa vie, son oeuvre. Mémoires de la Societé Zoologique de France, v.21, p.1-469, 1908.

LE ROY, G. Introduction. In: CONDILLAC, E. B. abbé de. Oeuvres philosophiques de Condillac, Ed. G. Le Roy. Paris: Presses Universitaires de France, 1947-1951. 3v.

MAGNER, L. N. A History of Life Sciences. New York: Marcel Dekker, 1979.

MARCHANT, L. (Trad.) Lettres de Georges Cuvier à M. Pfaff sur l'histoire naturelle, la politique et la littérature: 1788-1792. Paris: V. Masson, 1858.

MARTINS, L. Al-C. P. A teoria da progressão dos animais de Lamarck. Campinas: Universidade Estadual de Campinas, 1993.

MORE, L. T. The Dogma of Evolution. Princeton: Princeton University, 1925.

PICAVET, F. Les idéologues. Essai sur l'histoire des idées et des théories scientifiques, philosophiques, religieuses etc. en France depuis 1789. Paris: F. Alcan, 1891.

QUATREFAGES, A. Charles Darwin et ses précurseurs Français. Paris: Baillière, 1870.

RICKEN, U. Les idéologues et la sensation transformée. In: BUSSE, W., TRABANT, J. Les idéologues. Amsterdam: J. Benjamin, 1986, p.19-43.

SZYFMAN, L. Remarques sur la méthodolgie de Jean Baptiste Lamarck. In: SCHILLER, J.

(Ed.) Colloque international Lamarck. Paris: Blanchard, 1971. p.243-60. Jean-Baptiste Lamarck et son époque. Paris: Masson, 1982.

VIREY, J. J. Nature. In: DÉTERVILLE. (Ed.) Nouveau dictionnaire d'histoire naturelle. Paris: Déterville, 1803. v. 15, p.358-414.

ZYRKLE, C. The Early History of Idea of Inheritance of Acquired Characters and Pangenesis. Transactions of the American Philosophical Society, v.35, p.91-151, 1946. 